\title{
Monomeric and oligomeric flavan-3-ols and antioxidant activity of leaves from different Laurus sp.
}

\author{
Aṇa F. Vinha, Luís F. Guido, Anabela S. G. Costa, Rita C. Alves and
}

M. Beatriz P. P. Oliveira

The phenolic profile and antioxidant activity of three endemic Laurus sp. from Portugal were analysed. Dried leaves of $L$. nobilis L., $L$. azorica (Seub.) Franco, and L. novocanariensis Rivas Mart., Lousã, Fern. Prieto, E. Días, J. C. Costa \& C. Aguiar, collected in the mainland and in the Azores and Madeira archipela-gos, respectively, were used to prepare different extracts (aqueous, ethanolic and hydroalcoholic). They were studied regarding their $\mathrm{DPPH}^{*}$ scavenging activity, total phenolic and flavonoid contents, and the main phenolic compounds were identified by HPLCDAD-ESI-MS/MS. Total flavonoid contents were 30.1, 46.3, and $36.7 \mathrm{mg}$ of epicatechin equivalents per g of sample (dry weight) for $\mathrm{L}$. nobilis, $\mathrm{L}$. azorica and

L. novocanariensis, respectively. Epicatechin was the major compound, representing $\sim 12.1 \%$ of total flavan-3-ols in L. nobilis, 25.6\% in L. azorica, and $\sim 19.9 \%$ in L. novocanariensis. Although all samples presented a similar phenolic profile, significant differences were observed in their total contents and anti-oxidant activity.

Laurus is a genus of evergreen trees belonging to the Lauraceae family, and three autochthonous species (Laurus nobilis L., Laurus azorica (Seub.) Franco and Laurus novocanariensis Rivas Mart., Lousã, Fern. Prieto, E. Días, J. C. Costa \& C. Aguiar) are described in Portugal.

L. nobilis L., commonly known as bay leaves, is widely distributed in the Mediterranean area. It is usually used as a spicy fragrance and flavoring agent in culinary purposes (particularly in traditional meat dishes, stews and rice $)^{1,2}$ and as a natural additive in cosmetics. ${ }^{3}$ Several studies have already been performed on its leaves and extracts, revealing their pharmacological properties and potential health benefits related to different phytochemical compounds. Infusions are generally used as carminatives, diuretics, anti-rheumatics, among others. $^{4,5}$ Anti-inflammatory, anticonvulsive and antioxidant properties have also been reported in several studies for bay leaves and their extracts. ${ }^{2,3,6,7}$

L. azorica (Seub.) Franco, known as wild laurel, is a native shrub or small tree from the Azores archipelago. ${ }^{8}$ It has been referenced in the Red book of endangered species, and consequently measures for conservation of this species have been suggested. ${ }^{9}$ L. azorica leaves are commonly used in folk medicine owing to their anti-ulcer and blood depurative properties, ${ }^{10}$ but contrary to L. nobilis, the use of this species for culinary purposes is not recommended due to the toxicity of its leaves. ${ }^{9}$

L. novocanariensis is the endemic laurel from the Madeira archipelago. The leaves are used in traditional cuisine and its essential oil is used in folk medicine due to its cicatrizing and anti-rheumatic properties (topic preparations). ${ }^{11}$

The polyphenolic profile of dry leaves of Portuguese endemic Laurus sp. (specially L. azorica and L. novocanariensis) is still, to some extent, unexplored. The aim of this work was, then, to compare the phenolic profile of these Laurus sp. with that of $L$. nobilis in order to evaluate the possibility to discriminate them chemically. Different extracts from $L$. nobilis, L. azorica and L. novocanariensis leaves were prepared and analysed regarding their total phenolic and flavonoid contents and anti-radical activity. The phenolic profile of the selected extracts was then analysed by HPLC-DAD-ESI-MS/MS and compared. 


\section{Results and discussion}

\section{Phytochemical contents}

The type of solvent is a key factor for the compound extraction. It highly influences the kinetics of phytochemical release from the solid matrix and, consequently, the chemical composition and antioxidant activity of the extracts. ${ }^{12}$ Aiming to define the best solvent to maximize the extraction of the antioxidant compounds from the samples under study, an experimental design was assayed, in which three different extraction solvents were tested: $100 \%$ water, $100 \%$ ethanol, and a hydroalcoholic mixture $(1: 1)$. The extraction time and temperature used were $60 \mathrm{~min}$ and $40^{\circ} \mathrm{C}$, respectively, based on previous studies performed in natural matrices which showed that the use of longer times and higher temperatures is not economically advantageous to extract this type of compound. ${ }^{13}$ The total phenolic and flavonoid contents were determined and the results are presented in Table 1 . According to the type of solvent, a wide range of variability was found among the bioactive compound contents $(p<0.05)$ of the different Laurus sp. analysed. The hydroalcoholic solvent showed the highest capacity to extract the phytochemical compounds under study, revealing a higher total content for $L$. azorica, followed by $L$. novocanariensis and L. nobilis (Table 1). Ethanol extracted less phytochemicals than the hydroalcoholic mixture. For comparison, distilled water was also used as the extraction solvent, however the use of ethanolic and hydroalcoholic solvents resulted in better extraction rates. Our results are in agreement with those of other authors who claim that phenolic compounds are often more soluble in organic solvents that are less polar than water. ${ }^{14,15}$ Indeed, previous studies conducted on dry leaves of L. nobilis using ethanol and water as solvents reported higher phenolic contents in ethanolic extracts than in aqueous ones (132 mg GAE per $\mathrm{g}$ and $62 \mathrm{mg}$ GAE per $\mathrm{g}$, respectively). ${ }^{7}$ More recently, Muñiz-Márquez et al. described a phenolic content of $17.32 \mathrm{mg} \mathrm{g}^{-1}$ of L. nobilis (from Mexico), by using ultrasound-assisted extraction (35\% ethanol) for 40 min. ${ }^{5}$ The differences found among the results available in

Table 1 Total phenolic and flavonoid content of three endemic Portuguese Laurus sp. leaves (L. nobilis L., L. azorica, and L. novocanariensis) ${ }^{a}$

\begin{tabular}{llll}
\hline & Extracts & $\begin{array}{l}\text { Phenolic } \\
\text { (mg GAE per g) }\end{array}$ & $\begin{array}{l}\text { Flavonoids } \\
\text { (mg ECE per g) }\end{array}$ \\
\hline L. nobilis & Aqueous & $14.37 \pm 0.79^{\mathrm{c}}$ & $14.12 \pm 0.93^{\mathrm{c}}$ \\
& Hydroalcoholic & $43.03 \pm 0.35^{\mathrm{a}}$ & $30.15 \pm 0.25^{\mathrm{a}}$ \\
L. azorica & Ethanolic & $31.09 \pm 0.31^{\mathrm{b}}$ & $20.88 \pm 0.88^{\mathrm{b}}$ \\
& Aqueous & $26.29 \pm 1.18^{\mathrm{b}}$ & $16.62 \pm 0.49^{\mathrm{c}}$ \\
& Hydroalcoholic & $62.40 \pm 0.68^{\mathrm{a}}$ & $46.32 \pm 0.87^{\mathrm{a}}$ \\
L. novocanariensis & Ethanolic & $35.23 \pm 0.92^{\mathrm{c}}$ & $25.59 \pm 0.66^{\mathrm{b}}$ \\
& Aqueous & $25.42 \pm 1.20^{\mathrm{c}}$ & $16.32 \pm 0.49^{\mathrm{c}}$ \\
& Hydroalcoholic & $53.41 \pm 0.62^{\mathrm{a}}$ & $36.71 \pm 1.88^{\mathrm{a}}$ \\
& Ethanolic & $31.67 \pm 1.38^{\mathrm{b}}$ & $25.44 \pm 1.13^{\mathrm{b}}$
\end{tabular}

${ }^{a}$ Data are reported as mean value \pm standard deviation (three measurements). Values were significantly different when $p<0.05$ (Tukey's HSD test). Within each column, for each species, different letters indicate significant differences. the literature highlight, once more, that extraction conditions and the polarity of solvents highly influence compound quantification. Moreover, for the same plant species, the content and profile of phenolics (secondary metabolites) can be strongly influenced by the soil and climate conditions of each area.

In general, the samples studied in this work presented a similar profile of the analysed compounds: total phenolics > flavonoids (regardless of the solvent used). The results also show that $L$. azorica leaves contain significantly higher ( $p<$ 0.05 ) amounts of these compounds, followed by $L$. novocanariensis and L. nobilis, which suggests differences between species.

\section{Phenolic characterization by HPLC-DAD-ESI-MS/MS}

The phenolic profiles of the extracts from L. nobilis, L. azorica, and $L$. novocanariensis leaves were investigated by chromatography coupled to a diode array detector and a mass spectrometer. A long chromatographic run (120 minutes), together with UV and mass spectra, enabled us to identify the flavan3-ols as the most abundant phenolics in the analysed laurel leaves. Fig. 1 shows the chromatogram obtained for the L. azorica hydroalcoholic extract. Five main chromatographic peaks can be clearly observed, which were identified as peaks 1, 3, 4, 5 and 6 . The UV spectra of all these peaks exhibited a maximum at 277-280 $\mathrm{nm}$, which suggested that they belong to the same family. Peak 4 ( $\left.\lambda_{\max } 238,277 \mathrm{~nm}\right)$ showed an abundant protonated molecule at $\mathrm{m} / \mathrm{z} 291$. Collisional activation in $\mathrm{MS}^{n}$ experiments gave fragment ions with $\mathrm{m} / \mathrm{z}$ 273, 165, 139 and 123, which correspond to the fragmentation pathways of the monomeric flavan-3-ols catechin and epicatechin. Standards of $(+)$-catechin and (-)-epicatechin were injected and the peak was identified as epicatechin. Catechin $(\mathrm{m} / \mathrm{z} 291$ in the mass spectrum) was identified in Fig. 1 as peak 2 . Only traces of this compound were found in the analysed laurel leaves (Table 2).

Peak $1\left(\lambda_{\max } 238,280 \mathrm{~nm}\right)$ shows a pseudomolecular ion at $\mathrm{m} / \mathrm{z} 1153$ which fragments into 579 and 867 ions. This peak was ascribed to the tetrameric flavan-3-ol (E)C-(E)C-(E)C-(E)C and the fragments at $\mathrm{m} / \mathrm{z} 579$ and 867 correspond to the flavan-3-ol dimer and trimer, respectively. As with other mass spectrometric techniques no differentiation between stereoisomers is possible and no information about the position and stereochemistry of the interflavanoid linkage $(4 \rightarrow 6$ or $4 \rightarrow 8)$ is available.

The observed $m / z 865$ for the peak $3\left(\lambda_{\max } 238,280 \mathrm{~nm}\right)$ in Fig. 1 is consistent with the presence of a trimeric flavan-3-ol (E)C-(E)C-(E)C. $\mathrm{MS}^{n}$ experiments on this compound yielded five main fragments: $m / z$ 713, 695, 533, 411, and 287. Retro Diels-Alder (RDA) fission in the trimer resulted in the ion $\mathrm{m} / \mathrm{z}$ 713 (neutral loss of $152 \mathrm{Da}$ ). Neutral losses of 152 Da through RDA fissions are very common and were found to be the most important fragmentation for structure elucidation both for trimers and dimers. The fragment ion $\mathrm{m} / \mathrm{z} 287$ was formed by RDA fission of the dimer and subsequent neutral loss of 124 through $\mathrm{H}_{2} \mathrm{O} / \mathrm{BFF}$ (benzofuran-formin) fission of $\mathrm{m} / \mathrm{z} 411$, which is also found in the $\mathrm{MS}^{n}$ spectrum. 


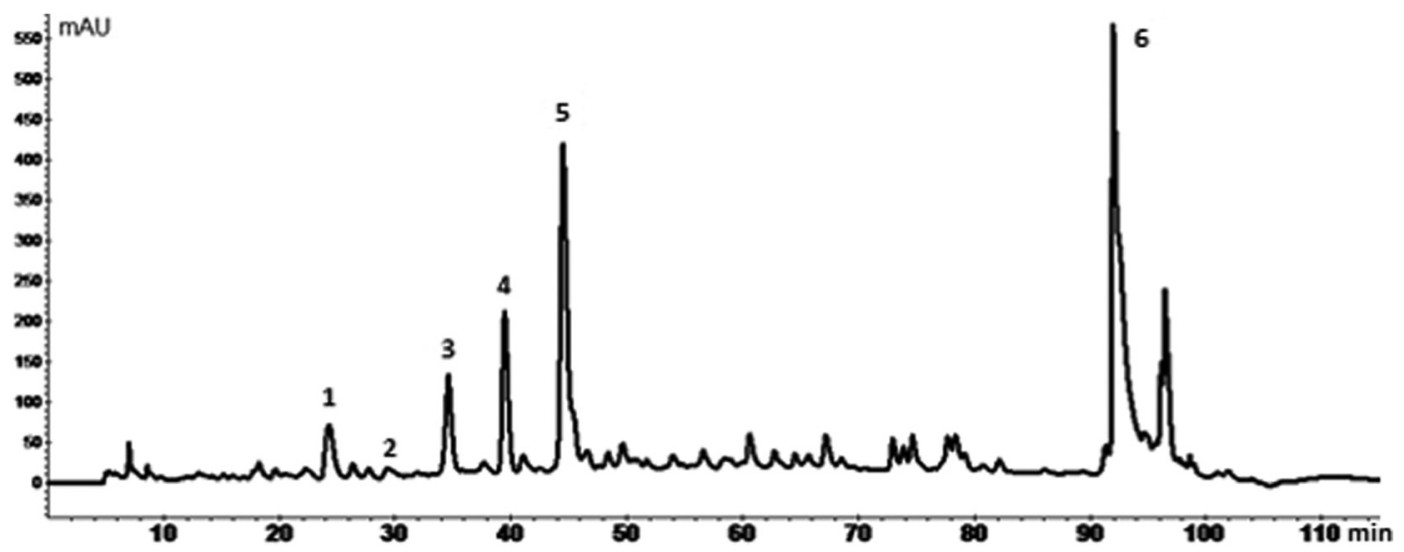

Fig. 1 HPLC-UV profile of the L. azorica hydroalcoholic extract, obtained at $280 \mathrm{~nm}$. Peak 1: tetrameric PA; peak 2: catechin; peak 3: trimeric PA 1; peak 4: epicatechin; peak 5: trimeric PA 2; peak 6: dimeric PA.

The pseudomolecular ion for peak 5 ( $\left.\lambda_{\max } 241,277 \mathrm{~nm}\right)$ gave $m / z$ 865. The fragmentation pattern of this compound was found to be almost analogous to the previous compound $(\mathrm{m} / \mathrm{z} 713,695,533,411,287)$ and thus a trimeric flavan-3-ol (E)C-(E)C-(E)C was ascribed to this peak.

The largest peak in the chromatogram (peak 6, Fig. 1) is characterized by maximum wavelengths of 241, 280 and $307 \mathrm{~nm}$ in the UV spectrum. This peak showed a protonated molecule at $m / z 577$ in the mass spectrum. The characteristic fragments at $m / z 425$ (RDA fission) were consistent with the presence of a dimeric flavan-3-ol (E)C-(E)C.

Proanthocyanidins can be divided into A-type and B-type. ${ }^{16}$ The latter are flavan-3-ol oligomers and polymers are linked mainly through $\mathrm{C} 4 \rightarrow \mathrm{C} 8$ and sometimes $\mathrm{C} 4 \rightarrow \mathrm{C} 6$ bonds, which cannot be elucidated here, as previously discussed. When an additional ether linkage is formed between $\mathrm{C} 2 \rightarrow \mathrm{O}$ $\rightarrow \mathrm{C} 7$, the compounds are classified as A-type proanthocyanidins. The molecular mass of 2 units lower $(\mathrm{m} / \mathrm{z} 577,865,1153)$ than that of the B-type $(\mathrm{m} / \mathrm{z} 579,867,1155$ found for dimers, trimers and tetramers, respectively) and a similar fragmentation pathway are indicators that the proanthocyanidins here found and characterized are A-type proanthocyanidins.

Very recently, among several other bioactive compounds analysed, Dias et al. described a procyanidin trimer (B- and A-type linkages), (-)-epicatechin, a procyanidin dimer, and $(+)$-gallocatechin as the four major flavan-3-ols, in this order, in wild laurus, which is in accordance with our results. ${ }^{17}$ It should be emphasized that our extracts have been further inspected for the presence of epigallocatechin $(\mathrm{m} / \mathrm{z} 307)$, epicatechin-3-gallate $(\mathrm{m} / \mathrm{z} 443)$ and epigallocatechin-3-gallate $(\mathrm{m} / \mathrm{z}$ 459), other major flavonoids found in tea leaves. ${ }^{18}$ However, these monomeric flavan-3-ols were not detected in the analysed extracts.

\section{Quantification of low molecular proanthocyanidins}

The content of monomeric and oligomeric flavan-3-ols found in the different species of Laurus is summarized in Table 2.
A-type proanthocyanidins were the major phenolics present in the three Laurus leaves investigated whereas epicatechin was the dominant flavan-3-ol monomer. Catechin, on the other hand, was the minor flavanol constituent, ranging from 0.04 to $0.96 \mathrm{mg} \mathrm{g}^{-1}$. The most abundant flavanol in the analysed Laurus extracts was the dimeric PA, followed by trimeric PA 2, trimeric PA 1 and tetrameric PA (Table 2). The epicatechin content ranged from $0.67 \mathrm{mg} \mathrm{g}^{-1}$ (L. nobilis ethanolic extract) to $13.71 \mathrm{mg} \mathrm{g}^{-1}$ (L. azorica hydroalcoholic extract).

The hydroalcoholic solvent allowed the highest recoveries of epicatechin from all samples according to the following order: L. azorica $>$ L. novocanariensis $>$ L. nobilis (13.71, 6.60

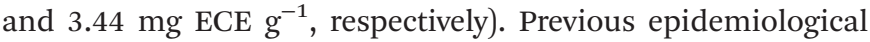
research related to dietary interventions in humans, using high flavanol-containing foods, substantiates an inverse relationship between the flavanol intake and the risk of cardiovascular diseases. ${ }^{19}$ Several potential flavanol-mediated bioactivities, including vasodilatation, ${ }^{20}$ insulin resistance, glucose tolerance, ${ }^{21}$ and improvement of immune and antioxidant defense systems, were also described. ${ }^{22}$ The highest total

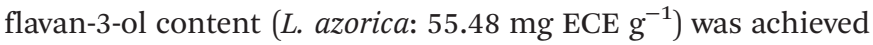
with the hydroalcoholic solvent. The lowest content (L. nobilis: $6.12 \mathrm{mg} \mathrm{ECE} \mathrm{g}^{-1}$ ) was obtained with the aqueous solvent.

Proanthocyanidins, better known as condensed tannins, are widely distributed throughout the plant kingdom, and are the second most abundant class of natural phenolic compounds after lignin. The estimated amount of total Laurus proanthocyanidins in this work ranges from $2.4 \%$ (L. nobilis) to $3.9 \%$ (L. azorica) on a dry weight basis, depending on the variety and geographic origin. These compounds exhibit general toxicity toward fungi, yeast and bacteria and are linked with plant defense mechanisms, organoleptic characteristics and stabilizing effects of pigments. ${ }^{23}$ The A-type proanthocyanidins here reported for the three endemic Portuguese Laurus sp. leaves, with their unusual second ether linkage, may result from the oxidative conversion of B-type into A-type, although this mechanism is still under investigation. ${ }^{15}$ 


\section{DPPH radical scavenging activity}

The $\mathrm{DPPH}^{*}$ scavenging activity is commonly used as a basic screening method for testing the antiradical activity of a large variety of compounds. ${ }^{24}$ This method is developed based on the ability of this stable free radical to change the color in the presence of antioxidant compounds. The $\mathrm{DPPH}^{*}$ contains an odd electron, which is responsible for a visible deep purple color in alcoholic solution, and the respective absorbance can be measured at $515 \mathrm{~nm}$.

The antioxidant activity of $L$. nobilis leaves was previously reported by using different solvents, including methanol/water extracts, ${ }^{3}$ infusions, ${ }^{4}$ ethanolic and aqueous extracts, ${ }^{7,25,26}$ but no similar study to this one has been done so far, comprising two endemic species coming from Madeira and Azores archipelagos (L. novocanariensis and L. azorica, respectively).

In this work, the antioxidant activity of aqueous, ethanolic and hydroalcoholic extracts of L. nobilis, L. azorica, and L. novocanariensis leaves was studied and the results are presented in Table 3. It can be pointed out that the extraction conditions also affected significantly the antioxidant activity of the extracts, but in contrast to what can be observed in Table 1, the highest scavenging activity was achieved with ethanol, for all the species in study. On the other hand, the hydroalcoholic mixture leads to intermediate values $(L$. azorica $\cong L$. nobilis > L. novocanariensis). According to the results presented in Table 1, also the aqueous extracts exhibited the worst antioxidant activity. As referred, ethanolic extracts presented higher antioxidant activity than the hydroalcoholic ones, showing that compounds other than those quantified in this study contribute to the antiradical properties of the extract. This can be expected due to the complexity of the matrix. Above all, the results of this study support that the concentration of bioactive compounds in plant extracts and their antioxidant activity vary according to the type of solvent used, as well as the plant species. However, further detailed examination of more methods would be advisable for the comprehensive assessment of antioxidant activity.

Table 3 Antioxidant activity measured by $\mathrm{DPPH}^{*}$ inhibition (\%) of Laurus sp. ${ }^{a}$

\begin{tabular}{|c|c|c|c|}
\hline \multirow[b]{2}{*}{ Laurus sp. } & \multicolumn{3}{|l|}{ Type of extract } \\
\hline & Aqueous & $\begin{array}{l}\text { Hydroalcoholic } \\
(1: 1)\end{array}$ & Ethanolic \\
\hline L. nobilis & $51.18 \pm 1.51^{\mathrm{cB}}$ & $76.11 \pm 0.09^{\mathrm{bA}}$ & $82.63 \pm 0.00^{\mathrm{aC}}$ \\
\hline L. azorica & $54.11 \pm 0.00^{\mathrm{cA}}$ & $75.07 \pm 0.09^{\mathrm{bA}}$ & $84.18 \pm 0.05^{\mathrm{aA}}$ \\
\hline L. novocanariensis & $23.65 \pm 0.33^{\mathrm{cC}}$ & $64.35 \pm 1.27^{\mathrm{bB}}$ & $83.10 \pm 0.09^{\mathrm{a} B}$ \\
\hline
\end{tabular}

${ }^{a}$ Data are reported as mean value \pm standard deviation (three measurements). Values were significantly different when $p<0.05$ (Tukey's HSD test). Within each column, different letters (A, B or C) indicate significant differences between plant species. Within each line, different letters ( $a, b$ or $c)$ represent significant differences between different types of extracts, for the same species. 


\section{Experimental}

\section{Reagents and standards}

Gallic acid, catechin, epicatechin, sodium acetate, FolinCiocalteu's phenol reagent, $\mathrm{DPPH}^{\bullet}$ (2,2-diphenyl-1-picrylhydrazyl), sodium nitrite, aluminum chloride, and formic acid (p.a.) were all purchased from Sigma-Aldrich (St. Louis, MO, USA). Sodium carbonate anhydrous, sodium hydroxide, acetonitrile (Lichrosolv HPLC grade), and absolute ethanol were obtained from Merck (Darmstadt, Germany). Ultrapure water was treated in a Milli-Q water purification system (Millipore, Bedford, MA, USA) and used to prepare all aqueous solutions. All other reagents are of analytical grade.

\section{Samples and sample preparation}

Three species of Laurus sp. identified as autochthonous plants in Portugal were collected in August of 2012. L. nobilis L. was collected from the mainland, in the North of Portugal, specifically in the district of Viana do Castelo (latitude: $41^{\circ} 44^{\prime} 31.57 \mathrm{~N}$, longitude: $8^{\circ} 52^{\prime} 32.68 \mathrm{~W}$ ); L. azorica (Seub.) Franco from Pico island in Azores archipelago (latitude: $38^{\circ} 31^{\prime} 35.7 \mathrm{~N}$, longitude: $28^{\circ} 19^{\prime} 08.7 \mathrm{~W}$ ), and L. novocanariensis from Funchal, Madeira archipelago (latitude: 32 39'39.0N, longitude: 16º $53^{\prime} 45.0 \mathrm{~W}$ ). Leaves were dried in a D6450 Hanau oven (Heraeus, Germany) at $25 \pm 2{ }^{\circ} \mathrm{C}$ for 3 weeks (in the dark). After that leaves were pulverized in a grinder Grindomix GM 200 (Retsch, Germany), and stored in amber vials tightly sealed, until further analysis.

\section{Extract preparation}

In order to study the optimal extraction conditions, different procedures were tested by varying the polarity of the extraction solvent. Each sample ( $\sim \mathrm{g})$ was extracted by stirring with $50 \mathrm{~mL}$ of solvent $(100 \%$ water, $50 \%$ water $/ 50 \%$ ethanol or $100 \%$ ethanol) for $1 \mathrm{~h}$ on a heating plate $\left(40{ }^{\circ} \mathrm{C}\right.$ at $\left.600 \mathrm{rpm}\right)$. Extracts were subsequently filtered through a Whatman no. 4 paper and stored at $-25{ }^{\circ} \mathrm{C}$ until analysis. All extractions were performed in triplicate.

\section{Determination of total phenolic compounds}

Total phenolics were determined as described by Costa et al. ${ }^{13}$ Briefly, $500 \mu \mathrm{L}$ of extract were mixed with $2.5 \mathrm{~mL}$ of the FolinCiocalteu phenol reagent $(1: 10)$ and $2 \mathrm{~mL}$ of a sodium carbonate anhydrous solution $(7.5 \%, \mathrm{~m} / \mathrm{v})$. The solution was incubated for $15 \mathrm{~min}$ at $45{ }^{\circ} \mathrm{C}$, followed by $30 \mathrm{~min}$ incubation (room temperature) in the absence of light. The absorbance was measured at $765 \mathrm{~nm}$. Total phenolic compounds were expressed as $\mathrm{mg}$ gallic acid equivalents (GAE) per $\mathrm{g}$ of dry plant material, using a gallic acid calibration curve $(r=$ 0.9990).

\section{Determination of total flavonoid content}

Total flavonoids were quantified by a colorimetric assay. ${ }^{13}$ Briefly, aliquots $(1 \mathrm{~mL})$ of each extract were diluted and mixed with $300 \mu \mathrm{L}$ of sodium nitrite. After $5 \mathrm{~min}$ of incubation (room temperature), $300 \mu \mathrm{L}$ of aluminum chloride were added, and after another minute $2 \mathrm{~mL}$ of sodium hydroxide $(1 \mathrm{M})$ and
$2.4 \mathrm{~mL}$ of ultrapure water were also added. The absorbance was measured at $510 \mathrm{~nm}$. A calibration curve was obtained for epicatechin $(r=0.9994)$ and the total flavonoid content was expressed as $\mathrm{mg}$ epicatechin equivalents (ECE) per $\mathrm{g}$ of dry weight.

\section{HPLC-DAD-ESI-MS/MS analysis}

The qualitative and quantitative analyses of the phenolic compounds in the extracts were performed by HPLC coupled with an ion-trap mass spectrometer and diode array detector (DAD). The HPLC system (Finnigan, Thermo Electron Corporation, San Jose, CA, USA) consisted of a low-pressure quaternary pump (Thermo Finnigan Surveyor), an auto-sampler (Thermo Finnigan Surveyor) with 200-vial capacity and a photodiode array detector (Thermo Finnigan Surveyor). The compounds were separated on a Phenomenex Synergi Hydro-RP C18 column $(150 \mathrm{~mm} \times 4.6 \mathrm{~mm}, 4 \mu \mathrm{m})$. A guard column with the same characteristics was also used. The chromatographic conditions were as follows: flow rate $0.3 \mathrm{~mL} \mathrm{~min}^{-1}$, sample injection volume of $25 \mu \mathrm{L}$, a mobile phase A (acetonitrile) and a mobile phase $\mathrm{B}(0.1 \%$ aqueous formic acid). The following gradient program was used: $10 \% \mathrm{~A}, 0 \mathrm{~min} ; 10 \%$ to $25 \% \mathrm{~A}$, over $80 \mathrm{~min} ; 25 \%$ A to $100 \%$, over $10 \mathrm{~min}$; $100 \%$ A, for $5 \mathrm{~min}$; back to $10 \% \mathrm{~A}$ in $10 \mathrm{~min}$; and $15 \mathrm{~min}$ of reconditioning before the next injection. An ion-trap mass spectrometer (Finnigan LCQ Deca XP Plus) coupled with an electrospray ionization (ESI) source and Xcalibur software Version 1.4 (Finnigan) were used for data acquisition and processing. The interface conditions were applied as follows: capillary temperature, $325{ }^{\circ} \mathrm{C}$; source voltage, $5.0 \mathrm{kV}$; capillary voltage, $4.0 \mathrm{~V}$; a sheath gas $\left(\mathrm{N}_{2}\right)$ flow rate at 90 arbitrary units and an auxiliary gas $\left(\mathrm{N}_{2}\right)$ flow rate at 25 arbitrary units. Data acquisition was performed between $\mathrm{m} / \mathrm{z} 200$ and 1500 . The positive ion polarity mode was selected due to a better signal-to-noise ratio in comparison with negative ion mode. Tandem mass spectrometric studies were performed $\left(\mathrm{MS}^{2}\right.$ and $\left.\mathrm{MS}^{3}\right)$. For the $\mathrm{MS}^{n}$ analyses $45 \%$ activation energy was applied. The quantitative analysis was conducted at $280 \mathrm{~nm}$ for monomeric flavan-3-ols (catechin and epicatechin) as well as for oligomeric flavan-3-ols. The concentrations of individual phenolics in extracts were determined using external standard calibration curves in the concentration range of 1 to $50 \mathrm{mg} \mathrm{\textrm {L } ^ { - 1 }}$. The analytical parameters of the calibration curves were calculated with the Excel program: catechin $(y=$ $0.0901 x-0.02, r=0.9998)$; epicatechin $(y=0.090 x+0.20, r=$ 0.9975). The molar response of dimers were previously found to be twice that of monomers. Assuming a 3-fold molar response for trimers and a 4 -fold molar response for tetramers, this allowed quantification of flavan-3-ol oligomers by the use of a monomeric external standard. Epicatechin was used in this case and the results for oligomers are reported as $\mathrm{mg}$ epicatechin equivalents (ECE) per $\mathrm{g}$ of dry sample, except for catechin ( $\mathrm{mg}$ catechin per g dry weight).

\section{Antioxidant activity evaluation}

Antioxidant activity of the extracts was evaluated by the $\mathrm{DPPH}^{*}$ (2,2-diphenyl-1-picrylhydrazyl) radical scavenging 
ability, according to the method previously described by Brand-Williams et al. ${ }^{27}$ with some modifications. An amount of $20 \mu \mathrm{L}$ of each extract was mixed with $180 \mu \mathrm{L}$ of a freshly prepared $\mathrm{DPPH}^{*}$ solution $\left(6.0 \times 10^{-5} \mathrm{~mol} \mathrm{~L}^{-1}\right.$ in ethanol). The decrease in the absorbance at $515 \mathrm{~nm}\left(A_{515}\right)$ of DPPH was measured in equal time intervals of $3 \mathrm{~min}$, in order to observe the kinetic reaction up to $20 \mathrm{~min}$, using a 96-well microplate (GENS5). The $\mathrm{DPPH}^{*}$ radical scavenging activity (RSA) (\%) was calculated using the following equation: $\left.\left[\left(A_{\mathrm{c}}-A_{\mathrm{s}}\right) / A_{\mathrm{c}}\right)\right] \times 100$, where $A_{\mathrm{c}}$ is $A_{515}$ of the blank sample not treated with any extract and $A_{\mathrm{s}}$ is $A_{515}$ of the sample in the presence of extract.

\section{Conclusions}

In conclusion, the results of in vitro assays of the examined L. nobilis L., L. azorica and $L$. novocanariensis expressed significant differences in phenolic contents. In addition, the hydroalcoholic mixture was selected as the best solvent for the extraction of the bioactive compounds analysed in this study. In turn, ethanolic extracts exhibited higher antioxidant activity, showing the possible contribution of additional compounds, than those previously referred. L. azorica leaves, regardless of the solvent used, and presented the highest content of total flavan-3-ols, followed by $L$. novocanariensis and $L$. nobilis L., respectively.

\section{Acknowledgements}

R. Alves is grateful to Fundação para a Ciência e a Tecnologia (FCT) for a post-doc grant (SFRH/BPD/68883/2010) financed by POPH-QREN and subsidized by FSE and MCTES. This work received financial support from the European Union (FEDER funds through COMPETE) and National Funds (FCT) through project Pest-C/EQB/LA0006/2013, as well as from FEDER funds under the framework of QREN through Project NORTE-070124-FEDER-000069.

\section{References}

1 D. J. M. Gómez-Coronado and C. Barbas, J. Agric. Food Chem., 2003, 51, 5196-5201.

2 O. Ouchikh, T. Chahed, R. Ksouri, M. B. Taarit, H. Faleh, C. Abdelly, M. E. Kchouck and B. Marzouk, J. Food Comp. Anal., 2011, 24, 103-110.

3 F. Conforti, G. Statti, D. Uzunov and F. Menichini, Biol. Pharm. Bull., 2006, 29, 2056-2064.

4 S. Dall'Acqua, R. Cervellati, E. Speroni, S. Costa, M. Guerra, L. Stella, E. Greco and G. Innocenti, J. Med. Food, 2009, 12, 869-876.
5 D. B. Muñiz-Márquez, G. C. Martínez-Ávila, J. E. Wong-Paz, R. Belmares-Cerda, R. Rodríguez-Herrera and C. N. Aguilar, Ultrason. Sonochem., 2013, 20, 1149-1154.

6 M. Polovka and M. Suhaj, Food Chem., 2010, 119, 391-401.

7 C. Ramos, B. Teixeira, I. Batista, O. Matos, C. Serrano, N. R. Neng, J. M. F. Nogueira, M. L. Nunes and A. Marques, Nat. Prod. Res., 2012, 6, 518-529.

8 R. Ballabio and P. Goetz, Phytothérapie, 2010, 8, 141-144.

9 R. F. Baptista, M.Sc. thesis, University of Coimbra, Portugal, 2012.

10 B. Ferrari, P. Castilho, F. Tomi, A. I. Rodrigues, M. C. Costa and J. Casanova, Phytochem. Anal., 2005, 16, 104-107.

11 D. Rivera and C. Obón, J. Ethnopharmacol., 1995, 46, 73-93.

12 I. Ignat, I. Volf and V. I. Popa, Food Chem., 2011, 126, 18211835.

13 A. S. G. Costa, R. C. Alves, A. F. Vinha, S. V. P. Barreira, M. A. Nunes, L. M. Cunha and M. B. P. P. Oliveira, Ind. Crops Prod., 2014, 53, 350-357.

14 F. F. Liu, C. Y. Ang and D. Springer, J. Agric. Food Chem., 2000, 48, 3364-3371.

15 S. M. A. Soutinho, R. P. F. Guiné, A. M. Jordão and F. J. Gonçalves, WASET, 2013, 79, 473-476.

16 D. Ferreira and D. Slade, Nat. Prod. Rep., 2002, 19, 517-541.

17 M. I. Dias, L. Barros, M. Dueñas, R. C. Alves, M. B. P. P. Oliveira, C. Santos-Buelga and I. C. Ferreira, Food Chem., 2014, 156, 339-346.

18 M. S. Lee, Y. S. Hwang, J. Lee and M. G. Choung, Food Chem., 2014, 158, 351-357.

19 I. C. Arts and P. C. Hollman, Am. J. Clin. Nutr., 2005, 81, 317S-325S.

20 M. Gómez-Guzmán, R. Jiménez, M. Sánchez, M. J. Zarzuelo, P. Galindo, A. M. Quintela, R. LópezSepúlveda, M. Romero, J. Tamargo, F. Vargas, F. PérezVizcaíno and J. Duarte, Free Radicals Biol. Med., 2012, 52, 70-79.

21 A. Bettaieb, M. A. V. Prieto, C. R. Lanzi, R. M. Miatello, F. G. Haj, C. G. Fraga and P. I. Oteiza, Free Radicals Biol. Med., 2014, 72, 247-256.

22 H. Sies, T. Schewe, C. Heiss and M. Kelm, Am. J. Clin. Nutr., 2005, 81, 304S-312S.

23 H. J. Li and M. L. Deinzer, J. Agric. Food Chem., 2006, 54, 4048-4056.

24 O. P. Sharma and T. K. Bhat, DPPH antioxidant assay revisited, Food Chem., 2009, 113, 1202-1205.

25 M. Elmastaş, I. Gülçin, Ö. Işildak, Ö. I. Küfrevioğlu, K. Ibaoğlu and H. Y. Aboul-Enein, J. Indian Chem. Soc., 2006, 3, 258-266.

26 A. M. Emam, M. A. Mohamed, Y. M. Diab and N. Y. Megally, Drug Discovery Ther., 2010, 4, 202-207.

27 W. Brand-Williams, M. E. Cuvelier and C. Berset, LWT-Food Sci. Technol., 1995, 28, 25-30. 